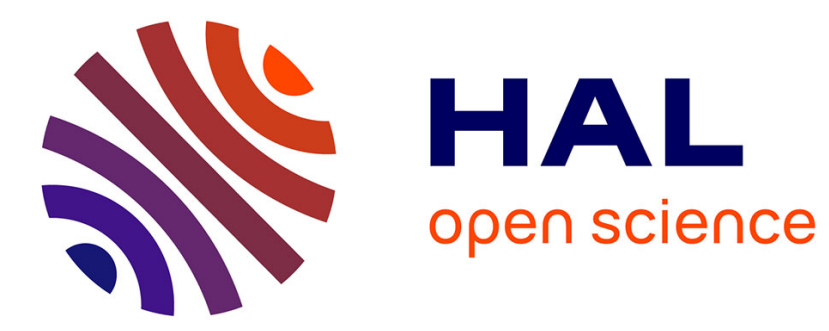

\title{
Synthesis of 3,5-Disubstituted 1,2-Dioxolanes through the Use of Acetoxy Peroxyacetals
}

Alexis Pinet, Thuy Linh Nguyen, Guillaume Bernadat, Bruno Figadère, Laurent Ferrié

\section{- To cite this version:}

Alexis Pinet, Thuy Linh Nguyen, Guillaume Bernadat, Bruno Figadère, Laurent Ferrié. Synthesis of 3,5-Disubstituted 1,2-Dioxolanes through the Use of Acetoxy Peroxyacetals. Organic Letters, 2019, 21 (12), pp.4729-4733. 10.1021/acs.orglett.9b01616 . hal-02271180

\author{
HAL Id: hal-02271180 \\ https://hal.science/hal-02271180
}

Submitted on 26 Aug 2019

HAL is a multi-disciplinary open access archive for the deposit and dissemination of scientific research documents, whether they are published or not. The documents may come from teaching and research institutions in France or abroad, or from public or private research centers.
L'archive ouverte pluridisciplinaire HAL, est destinée au dépôt et à la diffusion de documents scientifiques de niveau recherche, publiés ou non, émanant des établissements d'enseignement et de recherche français ou étrangers, des laboratoires publics ou privés. 


\title{
Synthesis of 3,5-Disubstituted 1,2-Dioxolanes Through the Use of Acetoxy-Peroxyacetals
}

\author{
Alexis Pinet, $\dagger$ Thuy Linh Nguyen, $\uparrow \dagger$ Guillaume Bernadat, $\dagger$ Bruno Figadère, $\dagger$ Laurent Ferrié. $\dagger^{*}$ \\ † BioCIS, Université Paris-Sud, CNRS, Université Paris-Saclay, Chatenay-Malabry, 92290 (France). \\ $\$$ Institute of Marine Biochemistry-Vietnam Academy of Science and Technology (VAST), Cau Giay, Hanoi, Vietnam. \\ Supporting Information Placeholder
}

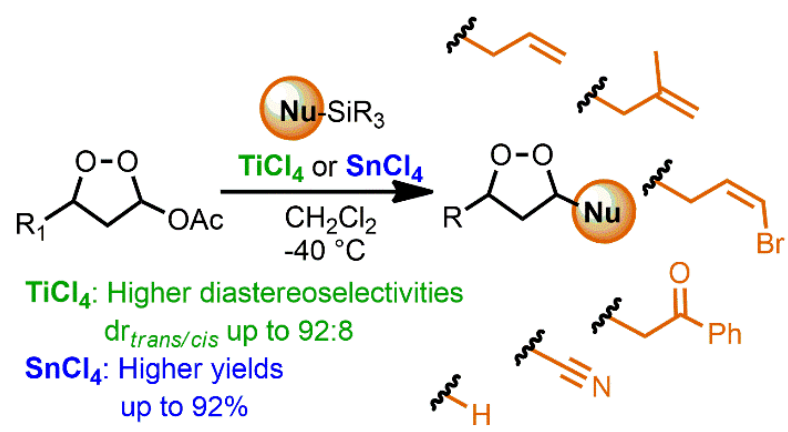

\begin{abstract}
The synthesis of acetoxy-endoperoxyacetal derivatives allowed the formation of functionalized 3,5-disubstituted-1,2dioxolanes through the formation of reactive peroxycarbenium species under Lewis acid mediation. The introduction of a neutral nucleophile such as allylsilanes, silanes, or silyl enol ethers was accomplished with moderate to good yields. The two studied Lewis acids, $\mathrm{TiCl}_{4}$ and $\mathrm{SnCl}_{4}$, gave contrasted results. The higher diastereoselectivity towards the trans diastereomer in experiments with $\mathrm{TiCl}_{4}$ as Lewis acid was explained by a faster degradation of the cis isomer product, conducting generally to lower yields. A rationalization of this result was supported by calculation.
\end{abstract}

Organic peroxides are uncommon moieties for natural products. ${ }^{1}$ Nevertheless, this pharmacophore is often source of potent biological properties due to the relative reactivity of peroxides. Besides the famous anti-malarial agent, artemisinin, isolated from Artemesia аппиа plant, ${ }^{2}$ many other organisms produce peroxide containing natural products. Particularly, plakinic acids, isolated from sponges Plakortis sp., exhibit a fatty acid structure with a 1,2-dioxolane ring between positions 3 and 5 (Figure 1). Another characteristic of plakinic acids is that the 1,2-dioxolane ring is 3,3,5,5-tetra-substituted. More recently, we investigated the synthesis of simpler analogues of mycangimycin, $\square$ a new peroxide isolated from Streptomyces sp. living in symbiosis with insect Dendrocton frontalis. ${ }^{\square} \mathrm{My}$ cangimycin has a very similar structure compared to plakinic acids but beside its highly conjugated fatty chain, the 1,2-dioxolane ring is only 3,5-disubstituted (Figure 1). This difference of structure is detrimental for the synthesis of this compound. Indeed, the substitution pattern present in the dioxolane ring of plakinic acids facilitates the preparation of such compounds due to the enhanced stabilization of intermediate carbenium or radical species necessary to provide the expected structure. ${ }^{\square}$ Precursor of 3,5-tetrasubstituted dioxolane rings can also be double bonds though peroxymercuration, ${ }^{\square}$ and here again, the substitution of starting olefins for mycangimycin derivatives is detrimental to the reactivity of the required olefin. For these reasons, relatively few examples of preparation of 3,5-disubstituted 1,2dioxolanes are found in the literature. ${ }^{6}$

Peroxycarbenium ions have emerged as a powerful tool for the synthesis of organic peroxides. ${ }^{\square}$ Nevertheless, the synthesis of 3,5-disubstituted 1,2-dioxolanes from the corresponding peroxyacetals is still an issue due to a reduced stabilization of the oxycarbenium ion as intermediate. Moreover, disfavoured withdrawing effect by induction of one oxygen atom to the other at the peroxide moiety reduces the ability to stabilize the peroxycarbenium compared to a classical acetal. Indeed, we planned to use in early experiments some reported methodologies from Dussault et al $^{8 \mathrm{~b}}$ to perform the nucleophilic addition to peroxyacetal such as methoxyperoxyketal 6, which has been prepared from hemiperoxyketal $\mathbf{4}$ by acid mediated metathesis with $\mathrm{MeOH} . \square$ However, to our disappointment, we were unable to prepare entity 7 from hemiperoxyacetal 5 (prepared from cyclopropanol by oxidative ring opening with triplet oxygen, see supporting information) and any simple alcohol. By analogy with tetrahydrofurans, we decided to activate the cyclic peroxyacetal as acetate, due to its known excellent leaving group ability.

In the first attempts, we experienced issues to obtain acetate 8 under classical conditions involving pyridine and $\mathrm{Ac}_{2} \mathrm{O}$, but only decomposition was observed, which can explain that a similar structure was scarcely reported. ${ }^{10}$ Fortunately the preparation of such a compound was possible by using Lewis acid- 
catalysed acetylation condition. With rare earth triflates such as $\mathrm{Yb}(\mathrm{OTf})_{3}$, we obtained expected acetate $\mathbf{8}$ in high yield. It is worth noting that stability of this compound is pretty high compared to THF acetate derivatives due to a reduced stabilization of the peroxycarbenium compared to THF oxycarbeniums, and thus compound $\mathbf{8}$ can then be generally purified by flash chromatography on silica gel without notable decomposition.

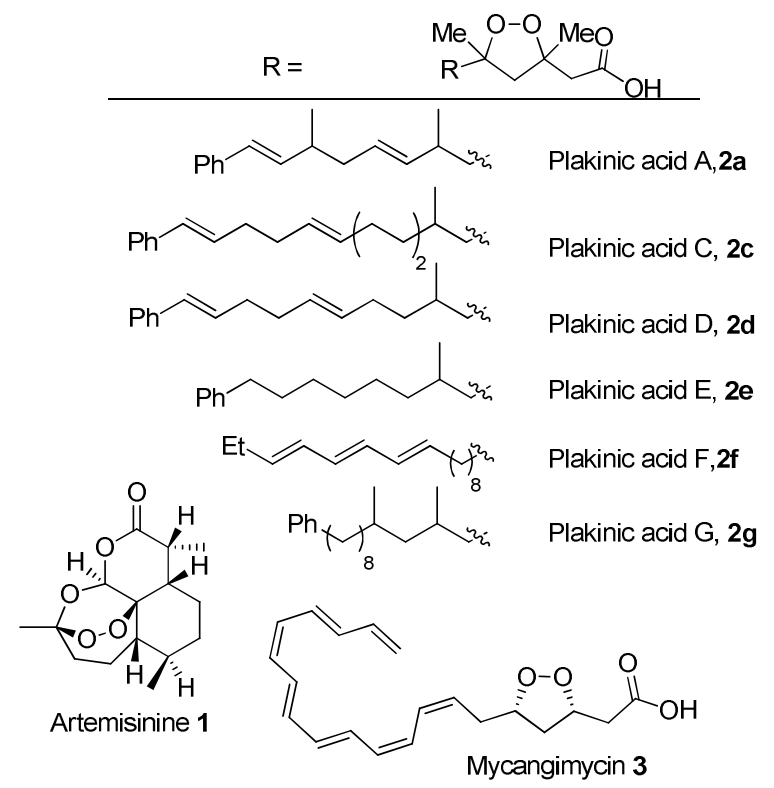

Figure 1. Artemisinin, plakinic acids and mycangimycin

Scheme 1. Activation of endoperoxy-ketals and -acetals.

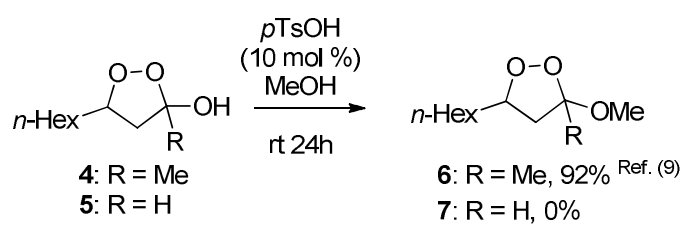

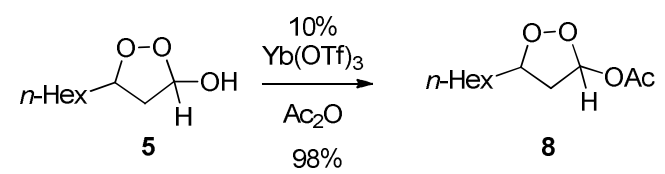

A Sakurai reaction between peroxyacetal $\mathbf{8}$ and allyltrimethylsilane 9 was then investigated, searching optimized reaction conditions. Dichloromethane was found to be the most suited solvent for this reaction. TMSOTf or $\mathrm{BF}_{3} \cdot \mathrm{OEt}_{2}$ were ineffective promoters for this transformation, converting only small amounts of starting material (Table 1, entries 1 and 2). In contrast, $\mathrm{SnCl}_{4}$ and $\mathrm{TiCl}_{4}$ were far more promising. Indeed, $\mathrm{SnCl}_{4}$ gave a high isolated yield of dioxolane $\mathbf{1 0}$ (Table 1, entry 4) at $-40{ }^{\circ} \mathrm{C}$. At lower temperature (entry 3 ), the reaction hardly proceeded with recovery of starting material after one hour. Extended reaction time did not improve significantly the yield and/or the diastereoselectivity. At higher temperature, the yields also decreased due to some degradations (Table 1, entries 5 and 6). The observed diastereoselectivity is moderated, in contrast to those observed on 2,4-disubstituted THF derivatives. ${ }^{11}$ This limited selectivity could be attributed to a competition between two conformers of the peroxycarbenium species. We also turned our attention to $\mathrm{TiCl}_{4}$; similarly to $\mathrm{SnCl}_{4}$ the reaction must be conducted at $-40{ }^{\circ} \mathrm{C}$ (Table 1 , entry 8 ) rather than $-78{ }^{\circ} \mathrm{C}$ (Table 1 , entry 7). However, in contrast to $\mathrm{SnCl}_{4}$, diastereoselectivity for 1,2-dioxolane $\mathbf{1 0}$ was largely improved up to $85: 15$, albeit with a lower yield. To explain this enhancement, we suspected reaction product $\mathbf{1 0}$ to endure a selective degradation of the cis isomer, therefore enriching the proportion of trans isomer but decreasing overall yield. Indeed, this hypothesis was confirmed by adjusting the number of equivalents of $\mathrm{TiCl}_{4}$ to the reaction mixture. Increasing the stoichiometry of $\mathrm{TiCl}_{4}$ to 1.1 equivalent decreased the yield but increased diastereoselectivity to 91:9 (Table 1, entry 9), while decreasing the amount of $\mathrm{TiCl}_{4}$ to 0.7 equivalent improved the yield but decreased diastereoselectivity of $\mathbf{1 0}$ to 70:30 (Table 1, entry 10).

Table 1. Screening of Lewis acid, stoichiometry and temperature on the Sakurai reaction between acetoxyperoxyketal 8 and allyITMS 9.

\begin{tabular}{|c|c|c|c|c|c|}
\hline \multirow[b]{2}{*}{ Entry } & 8 & \multicolumn{2}{|c|}{$\begin{array}{c}\text { Lewis acid (equiv) } \\
\underset{\mathrm{CH}_{2} \mathrm{Cl}_{2}}{\stackrel{\text { temperature }}{\longrightarrow}} \\
0.25-1 \mathrm{~h}\end{array}$} & $l_{10}^{O-C}$ & \multirow[b]{2}{*}{$\begin{array}{c}\mathrm{dr}^{b} \\
\text { (trans:cis) }\end{array}$} \\
\hline & $\begin{array}{l}\text { Lewis } \\
\text { acid }\end{array}$ & $\begin{array}{c}\text { Equiva- } \\
\text { lent }\end{array}$ & Temperature & $\begin{array}{c}\text { Yield }^{a} \\
(\%)\end{array}$ & \\
\hline 1 & TMSOTf & 0.1 or 1 & $-78^{\circ} \mathrm{C}$ to $\mathrm{rt}$ & $<10$ & $\mathrm{nd}^{c}$ \\
\hline 2 & $\mathrm{BF}_{3} \cdot \mathrm{OEt}_{2}$ & 1.0 & $-78^{\circ} \mathrm{C}$ to $\mathrm{rt}$ & 19 & $\mathrm{nd}^{c}$ \\
\hline 3 & $\mathrm{SnCl}_{4}$ & 0.9 & $-78^{\circ} \mathrm{C}$ & $13^{d}$ & $50: 50$ \\
\hline 4 & $\mathrm{SnCl}_{4}$ & 0.9 & $-40^{\circ} \mathrm{C}$ & 80 & $65: 35$ \\
\hline 5 & $\mathrm{SnCl}_{4}$ & 0.9 & $0{ }^{\circ} \mathrm{C}$ & 31 & $78: 22$ \\
\hline 6 & $\mathrm{SnCl}_{4}$ & 1.0 & $\mathrm{rt}$ & $-e$ & $-e$ \\
\hline 7 & $\mathrm{TiCl}_{4}$ & 0.9 & $-78^{\circ} \mathrm{C}$ & $7^{d}$ & $75: 25$ \\
\hline 8 & $\mathrm{TiCl}_{4}$ & 0.9 & $-40^{\circ} \mathrm{C}$ & 47 & $85: 15$ \\
\hline 9 & $\mathrm{TiCl}_{4}$ & 1.1 & $-40^{\circ} \mathrm{C}$ & 30 & $91: 9$ \\
\hline 10 & $\mathrm{TiCl}_{4}$ & 0.7 & $-40^{\circ} \mathrm{C}$ & 60 & $70: 30$ \\
\hline
\end{tabular}

${ }^{a}$ Isolated yield. ${ }^{b}$ Diastereomeric ratios were determined by ${ }^{1} \mathrm{H}$ NMR. ${ }^{c}$ Not determined. ${ }^{d} 50 \%$ of recovered starting material. ${ }^{e}$ Decomposition.

Scheme 2. Partial degradation of dioxolane 10 using reduced amount of $\mathrm{TiCl}_{4}$ under the reaction conditions of a Sakurai reaction

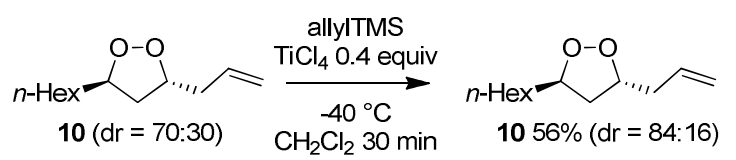

An additional experiment allowed us to confirm our hypothesis by applying Sakurai reaction conditions to dioxolane $\mathbf{1 0}$ with a reduced amount of $\mathrm{TiCl}_{4}(0.4$ equivalent). After $30 \mathrm{~min}$, the reaction mixture was quenched and purified to afford starting material in $56 \%$ recovered yield but with an improved diastereoselectivity in favour of the trans compound (from 70:30 to $84: 16$, Scheme 2).

The mechanism of this $\mathrm{TiCl}_{4}$ catalyzed degradation was further investigated and some major degradation products were identified. A $\mathrm{TiCl}_{4}$ catalysed Kornblum-DeLaMare rearrangement ${ }^{12}$ of dioxolane $\mathbf{1 0}$ afforded compounds $\mathbf{1 2}$ and $\mathbf{1 3}$ on one hand (Scheme 3, top route). On the other hand, $\mathrm{TiCl}_{4}$ mediated fragmentation of dioxolane $\mathbf{1 0}$ also afforded aldehyde $\mathbf{1 4}$ and ketone 15 from intermediate 11a. Under Sakurai reaction conditions, reactive species such as aldehyde $\mathbf{1 4}$ was converted into 
allyl adduct 18 (Scheme 3, bottom route). Presumably, a similar process occurred from intermediate 11b as well, but the expected degradation products were not produced in sufficient amount and also due to their relative volatility for some of them, side products 14, 16, 19, 20 and 21 were only observed from GC/MS analysis of the crude material and were not isolated. The mechanism of this fragmentation is not completely clear on our system, since the possibility of a retro-aldol reaction from 1,3-hydroxyketones $\mathbf{1 2}$ and $\mathbf{1 3}$ cannot be completely excluded. However a similar fragmentation was studied on 3,3,4-trisubstituted 1,2-dioxolanes with $\mathrm{TiCl}_{4}$, affording ketones and aldehydes with migration of an alkyl group, an hydrogen or a deuterium. ${ }^{13}$ An analogous fragmentation was also observed in one of our previous work, where a bicyclic peroxyketal afforded a ketoester under triflic acid activation. ${ }^{4}$ These two examples show that a retro-aldol process might not occur since it cannot explain the formed product. Here, the migration of the proton from position 3 or 5 to the position 4 of the 1,2-dioxolane ring is probably concomitant with the peroxide bond and carboncarbon bond cleavage (Scheme 3).

Scheme 3. Identification of $\mathrm{TiCl}_{4}$ mediated degradation products of dioxolane 10 .

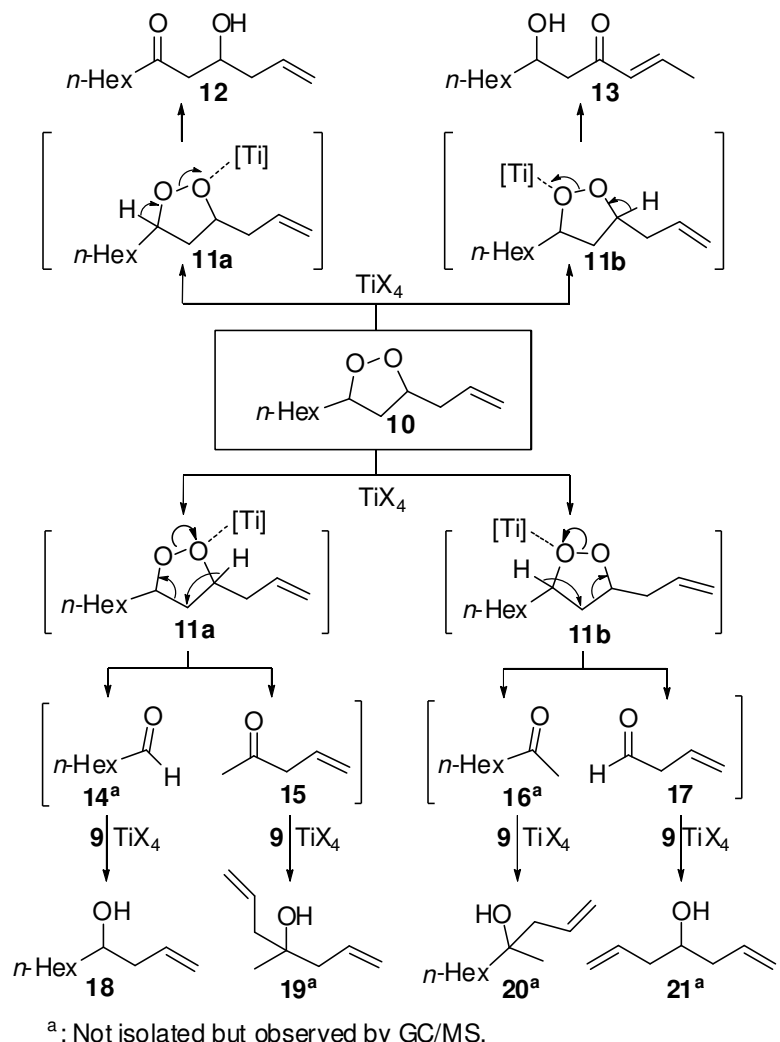

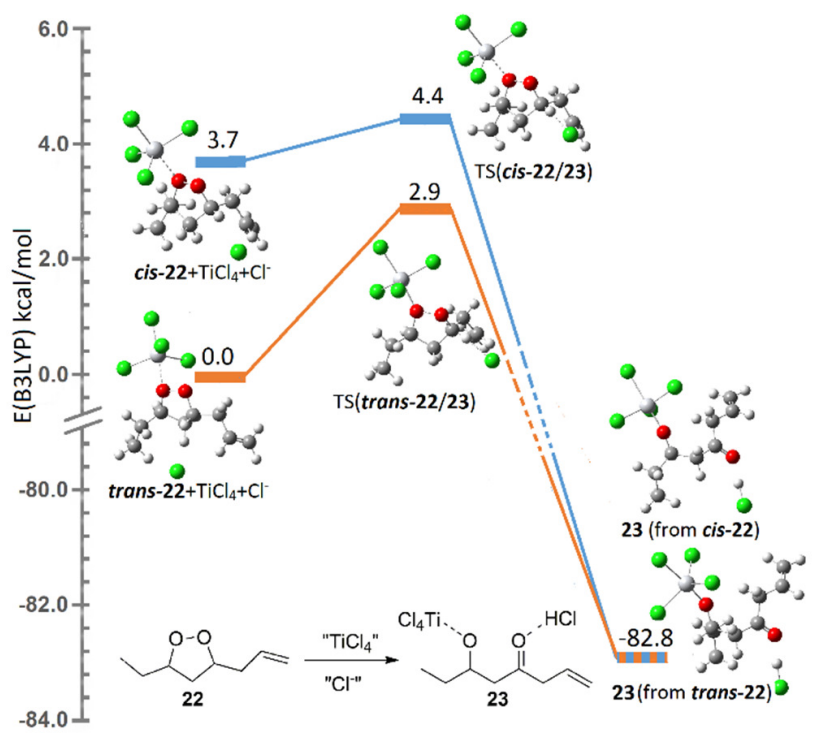

Figure 2. Energy profiles of the $\mathrm{TiCl}_{4}$ mediated KornblumDeLaMare rearrangements of model compound cis and trans-22 at the B3LYP/(6-31+G(d,p), LanL2DZ) level of theory. Electronic energy along the coordinates is represented in $\mathrm{kcal} / \mathrm{mol}$ relative to [trans-22+ $\mathrm{TiCl}_{4}+\mathrm{Cl}^{-}$. A chloride anion was used as a base to scavenge the proton freed in the reaction.

Table 2. Addition of various nucleophiles to peroxyacetal $8^{a}$

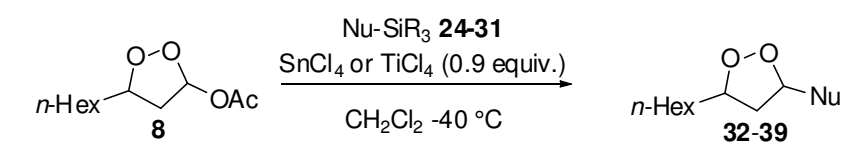

\begin{tabular}{|c|c|c|c|c|}
\hline entry & $\mathrm{Nu}-\mathrm{SiR}_{3}$ & $\begin{array}{l}\text { Lewis } \\
\text { acid }\end{array}$ & product & $\begin{array}{c}\text { yield }(\%)^{b} \\
(\mathrm{dr} \text { trans:cis })^{c}\end{array}$ \\
\hline 1 & & $\mathrm{SnCl}_{4}$ & & $79(40: 60)$ \\
\hline 2 & & $\mathrm{TiCl}_{4}$ & & $15(75: 25)$ \\
\hline 3 & & $\mathrm{SnCl}_{4}$ & & $38(80: 20)^{d}$ \\
\hline 4 & & $\mathrm{TiCl}_{4}$ & & $41(83: 17)^{d}$ \\
\hline 5 & & $\mathrm{SnCl}_{4}$ & & $30(80: 20)^{e}$ \\
\hline 6 & & $\mathrm{TiCl}_{4}$ & & $40(92: 08)^{e}$ \\
\hline 7 & & $\mathrm{SnCl}_{4}$ & & $70(35: 65)$ \\
\hline 8 & & $\mathrm{TiCl}_{4}$ & & $43(43: 57)$ \\
\hline 9 & & $\mathrm{SnCl}_{4}$ & & $77(40: 60)$ \\
\hline 10 & & $\mathrm{TiCl}_{4}$ & & $16(50: 50)$ \\
\hline 11 & $\begin{array}{c}\text { TMS-CN } \\
29\end{array}$ & $\mathrm{SnCl}_{4}$ & & 87 (50:50) \\
\hline 12 & TMS-N 3 & $\mathrm{SnCl}_{4}$ & & $78(50: 50)$ \\
\hline 13 & 30 & $\mathrm{TiCl}_{4}$ & & $32 \%(50: 50)$ \\
\hline 14 & $\mathrm{Et}_{3} \mathrm{Si}-\mathrm{H}$ & $\mathrm{SnCl}_{4}$ & & 66 \\
\hline 15 & 31 & $\mathrm{TiCl}_{4}$ & & 79 \\
\hline
\end{tabular}


${ }^{a}$ Reaction conditions: 8 ( 1 equiv.), $\mathrm{TiCl}_{4}$ or $\mathrm{SnCl}_{4}$ (0.9 equiv.), nucleophile 24-31 (3 equiv.). ${ }^{b}$ Isolated yield. ${ }^{c}$ Diastereomeric ratios were determined by ${ }^{1} \mathrm{H} N M R .{ }^{d} E: Z$ ratio $=1: 4\left({ }^{1} \mathrm{H} N M R\right) .{ }^{e} E: Z$ ratio $=1: 2\left({ }^{1} \mathrm{H}\right.$ NMR $)$.

Origin of the enhancement of the diastereoselectivity by degradation in the presence of $\mathrm{TiCl}_{4}$ in favour of trans compound was then investigated at the $B 3 L Y P /(6-31+G(d, p)$, LanL2DZ) ${ }^{1 \square}$ level of theory (Pople's basis set for organoelements and Los Alamos effective core potential for metallic centers). We focused our study on one of the two possible $\mathrm{TiCl}_{4}$ mediated Kornblum-DeLaMare rearrangements, leading to intermediate $\mathbf{2 3}$ from dioxolane $\mathbf{2 2}$, a simplified model of dioxolane 10 (Figure 2). Transition states starting from diastereoisomers cis-22 and trans-22 were localized on the potential energy surface. First attempts to search a pathway for the transition state from cis/trans-22 and $\mathrm{TiCl}_{4}$ only were unsuccessful. Introduction of a proton acceptor under the form of an additional chloride anion, which is likely to be found in the reaction medium, allowed the rearrangement to occur. The difference of activation energy $\Delta \Delta \mathrm{E}^{\ddagger}$ between the two diastereomers was found to be $2.2 \mathrm{kcal} / \mathrm{mol}$, in favour of isomer cis-22. This result is consistent with our observation about a faster degradation of cis-10 compared to trans-10 with $\mathrm{TiCl}_{4}$ and subsequent enrichment of this latter. The energy for $\left[\right.$ cis-22+TiCl $\left.4+\mathrm{Cl}^{-}\right]$is higher by $3.7 \mathrm{kcal} / \mathrm{mol}$ compared to the trans isomer, probably due to steric interactions between the two alkyl groups at the backside of the 1,2-dioxolane ring, squeezed by $\mathrm{TiCl}_{4}$ and chlorine placed on the front face. In contrast, the transition state for $\mathrm{cis}$ 22 is only $0.7 \mathrm{kcal} / \mathrm{mol}$ higher due to the free field for proton trapping by chlorine anion at the front face of the dioxolane ring. In the meantime, a steric congestion exists between chlorine and one alkyl group in the transition state for trans-22, demanding more energy $(2.9 \mathrm{kcal} / \mathrm{mol})$ to perform the reaction (Figure 2).

Table 3. Use of various peroxyacetals 40-45 and peroxyketal 46 in the Sakurai reaction with allyltrimethylsilane 9.

(1)

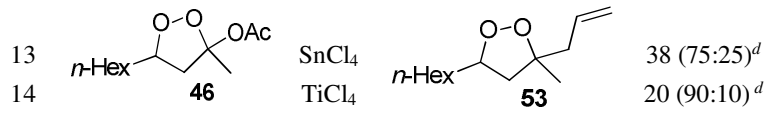

${ }^{a}$ Reaction conditions: 40-46 ( 1 equiv.), $\mathrm{TiCl}_{4}$ or $\mathrm{SnCl}_{4}$ (0.9 equiv.), allyltrimethylsilane ( 3 equiv.) in $\mathrm{CH}_{2} \mathrm{Cl}_{2}$ at $-40{ }^{\circ} \mathrm{C}$. ${ }^{b}$ Isolated yield. ${ }^{c}$ Diastereoselectivities were determined by ${ }^{1} \mathrm{H}$ NMR. ${ }^{d}$ Yield calculated over 2 steps from hemiperoxyketal precursor of acetate $\mathbf{4 6}$.

We then turned our attention to the nature of the nucleophile being able to react on endoperoxyacetal $\mathbf{8}$. The use of various allylsilanes proved to be successful (Table 2, entries 1-6). The selective degradation of $c$ is diastereoisomer with $\mathrm{TiCl}_{4}$ gave always better trans selectivity. Enol ethers were also screened as potent nucleophiles (Table 2, entries 7-10). The cis diastereoisomer was obtained as major product, although $\mathrm{TiCl}_{4}$ mitigated this result due to a selective degradation of cis diastereoisomer. Cyanide 29 was a very effective nucleophile with $\mathrm{SnCl}_{4}$ as well as azide $\mathbf{3 0}$ giving expected products $\mathbf{3 7}$ and $\mathbf{3 8}$ with excellent yields but no control of the diastereoselectivity. $\mathrm{TiCl}_{4}$ was not able to improve this result, resulting only in decreased yield (Table 2, entries 11-13). Reduction of the endoperoxyacetal is also possible with triethylsilane 31, producing 3-monosubstituted dioxolane 39 (entries 14 and 15).

Next, we explored substrates 40-46 (easily obtained as compound 8, see Supporting Information) in the Sakurai reaction with allylsilane 9. In order to improve the diastereoselectivity of the reaction, bulky dioxolanyl acetates 40-42 were studied (Table 3, entries 1-6). Unfortunately, these substrates did not improved diastereoselectivity compared to acetate $\mathbf{8}$ (Table 1), and a selective degradation of cis product was still observed when was used $\mathrm{TiCl}_{4}$ in most of the cases. Nevertheless, high steric congestion of the tert-butyl group for compound $\mathbf{4 2}$ seemed to suppress degradation of product 49, affording high yield of it using both Lewis acid. Benzyl substituted and protected alcohols are compatible in this reaction leading to good yield with $\mathrm{SnCl}_{4}$ and improved trans diastereoselectivity with $\mathrm{TiCl}_{4}$, as expected (Table 3, entries 7-11). Ketal derivative 46 was also examined with our protocol (Table 3, entries 13 and 14). Due to the improved stabilization of the peroxonium species with the methyl group, compound $\mathbf{4 6}$ proved to be unstable and could not be isolated cleanly. The crude material was used directly in the Sakurai reaction, meaning that the yield was calculated over two steps. Product $\mathbf{5 3}$ was obtained with a good selectivity with both $\mathrm{SnCl}_{4}$ and $\mathrm{TiCl}_{4}$. This result is comparable in yields (over 2 steps) with Dussault's procedure, meaning our methodology is not only limited to endoperoxyacetals. ${ }^{7 e, 15}$

In conclusion, we developed a new method for the formation of 3,5-disubstituted 1,2-dioxolanes through the use of acetoxyperoxyacetals and the formation of peroxycabenium intermediate species under $\mathrm{SnCl}_{4}$ or $\mathrm{TiCl}_{4}$ activation. The formation of acetoxyperoxyacetal by using a Lewis acid catalysis proved to be essential for their formation and allowed a sufficient reactivity for further functionalization. $\mathrm{SnCl}_{4}$ and $\mathrm{TiCl}_{4}$ were found to be the best Lewis acids screened so far. A wide variety of substrates and nucleophiles were compatible with the reaction conditions. A variation of results was observed between these two reagents: $\mathrm{SnCl}_{4}$ generally gave good yields but moderate selectivities, while $\mathrm{TiCl}_{4}$ furnished higher selectivity towards the trans products but generally lower yields. In this case, a $\mathrm{TiCl}_{4}$ mediated decomposition of the newly formed products takes place, where the cis-disubstituted dioxolane seems to decompose faster than the trans isomer, explaining improved selectivities and lower yields thus observed. Calculation 
about towards one degradation pathway could rationalize why cis-1,2-dioxolanes decompose more easily under treatment with $\mathrm{TiCl}_{4}$.

\section{AUTHOR INFORMATION}

\section{Corresponding Author}

*E-mail: laurent.ferrie@u-psud.fr

\section{ORCID}

Laurent Ferrié: 0000-0002-1171-205X

Bruno Figadère: 0000-0003-4226-8489

Guillaume Bernadat: 0000-0001-8955-0364

\section{Notes}

The authors declare no competing financial interest.

\section{ACKNOWLEDGMENT}

A.P. thanks the MESRI for a PhD fellowship, L.N. the USTH for a financial support. We thank Karine Leblanc and Jean-Christophe Jullian (BioCIS, Châtenay-Malabry) for HRMS analysis and NMR services, respectively. Leo Goehrs from Alionis is gratefully thanked for the donation of computing hardware.

\section{REFERENCES}

(1) (a) Casteel, D. A. Nat. Prod. Rep. 1999, 16, 55-73. (b) Liu, D.-Z.; Liu, J.-K. Nat. Prod. Bioprospect. 2013, 3, 161-206. (c) Vil, V. A.; Gloriozova, T. A.; Terent'ev, A. O.; Savidov, N.; Dembitsky, V. M. 2019, 103, 1627-1642. (d) Vil, V. A.; Terent'ev, A. O.; Savidov, N.; Gloriozova, T. A.; Poroikov, V. V.; Pounina, T. A.; Dembitsky, V. M. J. Steroid Biochem. Mol. Biol. 2019, 190, 76-87.

(2) (a) Klayman, D. L Science 1985, 228, 1049-1055. (b) Tu, Y. Nat. Med. 2011, 17, 1217-1220. (c) White, N. J. Science 2008, 320, 330334. (d) O'Neill, P. M.; Posner, G. H. J. Med. Chem. 2004, 47, $2945-$ 2964. (e) Haynes, R. K. Curr. Top. Med. Chem. 2006, 6, 509-537.
(3) Rahm, F.; Hayes, P. Y.; Kitching, W. Heterocycles, 2004, 64, 623-676.

(4) Nguyen, T. L; Ferrié, L. Figadère, B. Tetrahedron Letters 2016, 57, 5286-5289.

(5) (a) Scott, J. J.; Oh, D.-C.; Yuceer, M. C.; Klepzig, K. D.; Clardy, J.; Currie, C. R. Science 2008, 322, 63. (b) Oh, D.-C.; Scott, J. J.; Currie, C. R., Clardy, J. Org. Lett. 2009, 11, 633-636.

(6) Terent'ev, A. O.; Dmitry, A. B.; Vera, A. V.; Dembitsky, V. M. Beilstein J. Org. Chem. 2014, 10, 34-114.

(7) Bloodworth, A. J.; Bothwell, B. D.; Collins A. N.; Maidwell, N. L. Tetrahedron Lett., 1996, 37, 1885-1888.

(8) (a) Dussault, P. H.; Lee, H.-J.; Liu, X. J. Chem. Soc., Perkin Trans. 1 2000, 3006. (b) Dussault, P. H.; Lee, I. Q.; Lee, H.-J.; Lee, R. J.; Niu, Q. J.; Schultz, J. A.; Zope, U. R. J. Org. Chem. 2000, 65, 8407. (c) Ramirez, A.; Woerpel, K. A. Org. Lett. 2005, 7, 4617. (d) Dai, P.; Trullinger, T. K.; Liu, X.; Dussault, P. H. J. Org. Chem. 2006, 71, 2283. (e) Dussault, P. H., Liu, X. Org. Lett. 1999, 1, 1391-1393.

(9) Lifchits, O.; Mahlau, M.; Reisinger, C. M.; Lee, A.; Fares, C.; Polyak, I.; Gopakumar, G.; Thiel, W.; List, B. J. Am. Chem. Soc. 2013, 135, 6677-6693.

(10) (a) Witkowski, B.; Gierczak, T. J. Mass Spectrom. 2013, 48, 7988. (b) Baumstark, A. L.; Vasquez, P. C.; Chen, Y.-X. J. Org. Chem. 1994, 59, 6692-6696.

(11) Schmitt, A.; Reißig, H.-U. Eur. J. Org. Chem. 2000, 3893-3901.

(12) Yaremenko, I. A.; Vil', V. A.; Demchuk, D. V.; Terent'ev, A. O. Beilstein J. Org. Chem. 2016, 12, 1647-1748.

(13) Yoshida, M.; Miura, M.; Nojima, M.; Kusabayashi, S. J. Am. Chem. Soc. 1983, 105, 6279-6285.

(14) (a) Hohenberg, P.; Kohn, W. Phys. Rev. 1964, 136, B864-B871. (b) Kohn, W.; Sham, L. J. Phys. Rev. 1965, 140, A1133-A1138. (c) Becke, A. D. J. Chem. Phys. 1993, 98, 5648-5652. (d) Lee, C.; Yang, W.; Parr, R. G. Phys. Rev. B 1988, 37, 785-789 (e) Hehre, W. J.; Radom, L.; Schleyer, P. V. R.; Pople, J. A. /Ab Initio Molecular Orbital Theory/; Wiley: New York, 1986. (f) Hay, P. J., Wadt, W. R. J. Chem. Phys. 1985, 82, 270-283. (g) Hay, P. J., Wadt, W. R. J. Chem. Phys. 1985, 82, 299-310.

(15) Lu, X.; Liu, Y.; Sun, B.; Cindric, B.; Deng, L. J. Am. Chem. Soc. 2008, 130, 8134-8135 